\title{
1 Historical effect in the territoriality of Ayu fish
}

3 Yumi Tanaka ${ }^{1}$, Kei'ichiro Iguchi ${ }^{2}$, Jin Yoshimura ${ }^{3,4,5}$, Nariyuki Nakagiri ${ }^{1}$ and Kei-ichi

4 Tainaka $^{3 *}$

$5 \quad{ }^{1}$ School of Human Science and Environment, University of Hyogo, Himeji, 670-0092,

6 Japan (e-mail: Y.T.: nd08x012@stshse.u-hyogo.ac.jp, N.N.:

7 nakagiri@shse.u-hyogo.ac.jp).

$8 \quad{ }^{2}$ National Research Institute of Fisheries Science, Fisheries Research Agency, 1088

9 Komaki, Ueda 386-0031, Japan (e-mail: keyichi@fra.affrc.go.jp).

$10{ }^{3}$ Department of Systems Engineering, Shizuoka University, Hamamatsu 432-8561,

11 Japan (e-mail: J.Y.: jin@sys.eng.shizuoka.ac.jp, K.T.: tainaka@sys.eng.shizuoka.ac.jp)

$12{ }^{4}$ Marine Biosystems Research Center, Chiba University, 1 Uchiura, Kamogawa

13 299-5502, Japan.

$14{ }^{5}$ Department of Environmental and Forest Biology, State University of New York

15 College of Environmental Science and Forestry, Syracuse, New York 13210, USA.

*Corresponding author: Kei-ichi Tainaka

17

18 Keywords: fish behavior, territory formation, territory breakdown, historical effect,

19 phase transition 


\section{Abstract}

22 Ayu fish form algae-feeding territories in a river during a non-breeding (growing)

23 season. We build a cost-benefit theory to describe the breakdown and formation of

24 territory. In the early stage of a growing season, all fish hold territories at low densities.

25 Once all territory sites are occupied, excess fish become floaters. When fish density

26 further increases, a phase transition occurs: all the territories suddenly break down and

27 fish form a school. In contrast, when the fish density is decreased, territories are

28 suddenly formed from the school. Both theory and experiments demonstrate that ayu

29 should exhibit a historical effect: the breakdown and formation processes of territory are

30 largely different. In particular, the theory in formation process predicts a specific fish

31 behavior: an "attempted territory holder” that tries to have a small territory emerges just

32 before the formation of territory. 


\section{Introduction}

Animals have evolved various behavioral strategies as an adaptation for

different ecological circumstances (Krebs and Davies 1987). Territoriality and group

foraging are the two different ways of adaptation (Foster 1985). Territorial behavior is a

life history adaptation in the solitary state of animals (Brown and Orians 1970; Ebersole

1977; Davies and Houston 1984), while group foraging is an adaptation by forming a

group (Schaller 1972; Robertson et al. 1976). In many species, mating pairs often form

a breeding territory, while they forage in group during non-breeding seasons, e.g., most

of migratory birds. However, it is rather rare to see a transition between territoriality and group foraging in a single (non-breeding) season.

Whether territory formation is adaptive or not can be answered by usual the cost-benefit analysis comparing the individuals with/without a territory, within a solitary state (Krebs 1971). Group foraging is also compared with solitary foraging in a species with some group foraging (Pulliam and Caraco 1984; Clark and Mangel 1986). These two different evolutionary adaptations may occur in a closely related species, e.g.,

49 fishes (Foster 1985). However, it should be extremely rare to find both territorial foraging and group foraging in a single species. The cost-benefit analyses of these

51 behavioral strategies can provide a single framework to view the adaptive evolution of 
52 individual behavior (Stephens and Krebs 1986). We here provide such a unique case

53 study of a fish exhibiting both territorial behavior and group foraging (school) as

54 adaptive responses during a growing season (May to July).

Ayu (Plecoglossus altivelis, Osmeridae) is an endemic migratory fish in Japan

56 (Kawanabe 1969; Miyadi 1960; Takahashi and Azuma 2006). This fish has a unique life

57 history (Kawanabe 1969; Miyadi 1960; Iguchi 1996). Its life cycle is completed by one

58 year. Eggs that are spawned in the downstream of a river hatch in autumn. The hatched

59 larvae drift to a sea and feed mostly zooplankton in coastal zones. In spring, the juvenile

60 fish migrate to the midstream (and/or upstream) of a river, where algae (diatoms) grow

61 on the rocks of the riverbeds in rapids (swift current). Many young fish form a territory

62 in this stage (Fig. 1). They feed on these algae from spring to fall. In fall, when ayu fish

63 matures, they swim downstream all together. They spawn eggs and die soon afterwards.

64 Thus, ayu is a diadromous fish, but it is strictly anadromous (Iguchi 1996 ).

In the midstream of a river, rapids and pools usually locate in turn (Mizuno and Kawanabe, 1981). In the early stages of a growing season (May), the feeding territory is

67 formed in the rapids, where diatoms grow on the surfaces of rocks (Biggs and Hickey 1994; Biggs et al. 1998). In contrast, (deep) pools, without algae, are not suitable for ayu that can only feed on small amounts of drifted algae and insects. The amount of 
algae growing in one territory is several times more than the necessary amounts for one fish to grow to maturity (Iguchi and Abe 2002; Gill and Wolf 1975). During the growing season, many fish swim into a river and the fish density increases daily. Those that cannot hold a territory become a floater. A floater, usually staying in a pool, cannot feed well. It sometimes intrudes into a territory in the rapids and steals algae while intruding. In order to defend its own territory, the territory holder attacks a floater violently (Fig. 1). The unique “tomo-dsuri” fishing exploits such violent attacks: fishermen use a live decoy as an intruder to catch the territory holder. When the fish number in the midstream increases, all fish form a school. In contrast, when the fish number decreases, the state of fish conversely changes from school to territory. In the present paper, we estimate the fitness (Gross 1982; 1985; Tainaka et al. 2007; Tanaka et al. 2009) of an individual fish, and report a historical effect by the comparison between breakdown and formation processes of territories.

\section{2. Model}

85 An individual fish takes one of three strategies: territorial holder (Th), floater (Fl) and

86 school (Sc). The optimal strategies for the energy (food) gain of an individual fish 
87 depend not only on total fish density but also on the time difference of density. We

88 expect the breakdown and formation of a territory as illustrated in Fig. 2. First, we deal

89 with the case that the overall density $(N)$ increases. From the previous studies

90 (Kawanabe 1969; Iguchi 1996; Kawanabe 1958, 1970, 1973), we assume the following

91 three phases:

92 i) Th-phase

93 At low density, all fish can hold territories in the rapids and some territories are not

94 occupied (Kawanabe 1973). When the density of fish increases, all incoming fish can

95 hold a new territory in a vacant site, until all the territory sites are occupied ( $N \leq N_{T \text { max }}$ ).

96 Here $N_{T \max }$ is the maximal number (density) of territories.

97 ii) Coexisting phase: (Th+Fl)-phase

98 When the population size exceeds the territory capacity ( $N>N_{T \max }$ ), newcomers

99 cannot hold territories. These fish become a floater staying in the pool. Hence, we

100 suspect that a floater is not an available option, but a forced action. Each territory holder

101 defends own territory against intruders (floaters).

102 iii) Sc-phase 
103 Due to more newcomers, the number of floaters increases. Since territory intrusions by

104 floaters become frequent, territory holders have to spend much more time in defending

105 their own territory. They lose the time to feed on algae. When the density of fish

106 exceeds a critical density $\left(N_{1}\right)$, all the territories suddenly break down (Kawanabe 1958,

107 1970, 1973). For $N>N_{1}$, all fish form a school at once (Fig. 2).

108 In summary, in the increasing stage of density, the fish behavior changes as

$109 \mathrm{Th} \rightarrow(\mathrm{Th}+\mathrm{Fl}) \rightarrow$ Sc. The total density $(N)$ is represented by

$110\left\{\begin{array}{cc}N=N_{T} & \left(N \leq N_{T \max }\right) \\ N=N_{T}+N_{F} & \left(N_{T \max }<N \leq N_{1}\right) \\ N=N_{S} & \left(N_{1}<N\right)\end{array}\right.$

111 where $N_{T}, N_{F}$ and $N_{S}$ denote the densities of territorial holder, floater and school,

112 respectively.

At the high density, all fish form a school. However, even when the fish

114 density decreases less than the breakdown point $N_{1}$, territories cannot be observed. The

115 fish schools should persist up to a very low density, until every fish can hold a territory

116 at once. This is because the territory formation is very hard. When $N<N_{1}$, a fish has

117 two options: either to attempt to make a territory or remain in a school. We call the

118 former 'attempted territory holders' (Th*). Even if one fish attempts to hold a territory, 
119 other remaining fish become intruders. The defense against school fish is very hard,

120 while the defense against a solitary intruder is highly effective (Iguchi 1996; Tachihara

121 and Kimura 1992).

122 However, if the density becomes lower below a critical value $\left(N<N_{2}\right)$, then

123 territory holders can emerge at once. The formation point of territory $\left(N_{2}\right)$ can be

124 estimated by the timing when all fish can hold a territory, or when no fish are

125 necessarily forced to be a floater. When $N<N_{2}$, all fish become territory holders. The

126 formation point $N_{2}$ is much less than the breakdown point $N_{1}$, and it should be

127 almost equal to the maximum density $N_{T \max }$ of territory. In the decreasing stage, the

128 fish behaviors change as $\mathrm{Sc} \rightarrow \mathrm{Th}$. The density of each strategy is given by

$129 N= \begin{cases}N_{S} & N>N_{2} \\ N_{T} & N \leq N_{2}\end{cases}$

130 There is no forced option to be a floater in the decreasing stage (Fig. 2). The attempted

131 territory holder $\left(\mathrm{Th}^{*}\right)$ can emerge for $N_{1}>N>N_{2}$. 


\section{Theory}

\section{3-1. Cost-benefit theory in an increasing stage}

135 We estimate the fitness of an individual fish for three strategies: territorial holder (Th),

136 floater (Fl) and school (Sc). The fitness is composed of both cost and benefit, where the

137 cost is defined by a defense cost to protect a territory, and the benefit is assumed to be

138 the food amount each fish can eat.

139 When the overall density $N$ is increased, the choice changes according to the

140 following three phases:

141

i) Th-phase $\left(N \leq N_{T \max }\right)$

142 When all fish have territories, the fitness of a territory holder $\left(W_{T}\right)$ takes the maximum

143 value. Let $K_{r}$ be the algal food amount in the rapids, then $W_{T}$ can be expressed as

$144 \quad W_{T}=K_{r} / N_{T \max }=W_{T \max }=$ const.

145 ii) Coexisting phase $\left(N_{T \max }<N \leq N_{1}\right)$

146 The territory holder bumps its body against the intruding floater repeatedly until the

147 floater leaves its territory. Let $\tau_{f}$ and $\tau_{d}$ be the dimensionless ratios of the feeding 
148 and defense time durations of a territory holder, respectively $\left(\tau_{f}+\tau_{d}=1\right.$ ) (Brown

149 1964; Pyke 1979). The fitness of a territory holder $W_{T}$ can be expressed as

$150 \quad W_{T}=\left(K_{r} / N_{T \max }\right) \tau_{f}-c_{d F} \tau_{d}$

151 where $c_{d F}$ is the defense cost of a fish against a floater. For simplicity, we assume $\tau_{d}$

152 is a linear function of floater density:

$153 \tau_{d}=a N_{F}$

154 where $a$ is a constant. Equation (5) comes from the experimental data as listed in

155 Table 1. We find from this table that the attack frequency increases as the floater

156 number increases. Next, we evaluate the fitness $W_{F}$ of a floater. Since the floater is the forced

158 option, $W_{F}$ is always smaller than $W_{T}$. The floater fitness is not important to

159 determine the optimal strategy. Note the profile of $W_{F}$ has the following properties: (i)

160 if the density ( $N_{F}$ ) of floaters is low, $W_{F}$ is nearly constant. (ii) On the contrary, if

$161 N_{F}$ is high, $W_{F}$ may be represented by $K_{p} / N_{F}$, where $K_{p}$ is the food amount in 162 the pools.

163

iii) Sc-phase $\left(N>N_{1}\right)$ 
164 Now, we evaluate the fitness $W_{S}$ of a school fish for Sc-phase. Since the school fish

165 feeds both in the rapids and pools, the fitness of a school fish is given by

$166 W_{S}=\left(r K_{r}+K_{p}\right) / N$

167 where $r$ is the feeding rate of school fish in rapids relative to a territory holder $(r<1)$.

168 In Fig. 3, both $W_{F}$ and $W_{T}$ are depicted against the total density $N$. The breakdown

169 point $N_{1}$ of territoriality can be determined by

$170 \quad W_{S}=W_{T}$

171 In the above model, to guarantee the cross point at $N_{1}$, we assume that $K_{r}>r K_{r}+K_{p}$.

172 The optimal strategy is territory holder $\left(W_{T} \geq W_{S}\right)$ for $N \leq N_{1}$, while school fish is

173 optimal $\left(W_{S}>W_{T}\right)$ for $N>N_{1}$ (Fig. 3).

\section{3-2. Cost-benefit theory in a decreasing stage}

176 At high density, the fitness $W_{S}$ of school fish is same as that in the increasing stage

177 [see Eq. (6)]. With decreasing fish density $\left(N<N_{1}\right)$, the fitness $W_{S}$ becomes smaller

178 than $W_{T}$. Here a fish has two options: either to attempt to make a new territory or remain in a school. We specifically consider the fitness of an attempted territory holder 
$180\left(W_{T}^{*}\right)$. Note that there is an essential difference between increasing and decreasing

181 stages: in the increasing stage, the intruders are floaters, while in the decreasing stage

182 the intruders are school fish. Hence, the defense time ratio $\tau_{d}$ is proportional to the

183 density of school fish.

$184 \tau_{d}=a N_{S}$

185 The fitness $W_{T} *$ of an attempted territory holder can be expressed as

$186 \quad W_{T}^{*}=\left(K_{r} / N_{T \max }\right) \tau_{f}-c_{d S} \tau_{d}$

187 where $C_{d s}$ is the defense cost of a fish against school fish. Note that the defense cost

188 against school fish is much larger than that of floaters, such that $c_{d S}>>C_{d F}$. This

189 difference is very important. Below the critical density $\left(N<N_{2}\right)$, all school fish should

190 switch to the territory option; we have the critical point $\left(N_{2}\right)$ of territory formation by

$191 \quad W_{T}^{*}=W_{S}$

192 When all fish can hold a territory, they become territory holder. Their fitness jumps up

193 to the maximum value $W_{T \max }$. 


\section{3-3. Numerical estimations}

196 We insert the empirical data into the model to estimate the expected dynamics and transition points numerically. Since an ayu fish forms a territory of ca. 1 [m $^{2}$ ] (Miyadi 1960; Kawanabe 1973), we set that $N_{T \max }=1$ [ $/ \mathrm{m}^{2}$ rapids]. (We consider the fitness based on $1 \mathrm{~m}^{2}$ rapids in a midstream of a river.) In a typical Japanese river, the midstream consists of about $55 \%$ of rapids and about $45 \%$ of pools (Kawanabe 1973). This means that $1 \mathrm{~m}^{2}$ rapids are associated with 0.81 [ $\mathrm{m}^{2}$ pools]. The defense time $\left(\tau_{d}\right)$ and feeding time $\left(\tau_{f}\right)$ are estimated from empirical studies (Kawanabe 1969, Kawanabe 1970) as follows. Let $n_{f}$ and $n_{d}$ be the times (numbers: [/min]) of feeding and defense (attack), respectively, per one territory holder. The maximum number of defense in a minute is 15 times, whereas that of feeding is 30 times. Therefore, we get $\tau_{d}=n_{d} / 15$ and $\tau_{f}=n_{f} / 30=1-n_{d} / 15$, since $\tau_{d}+\tau_{f}=1$. Because the times of defense (attack) $n_{d}$,

207 increases with the number of floaters, we assume that $n_{d}=a N_{F}$. From low density $\left(N_{F} \leq\right.$

209 (Table 1). Therefore, we set $a=3.0$. 
212 against a floater is estimated between $0.01 \sim 0.2$ (Iguchi and Hino 1996), we set $c_{d F}=$

213 0.1. Numerically, we derive that $W_{T}=K_{r}-\left(K_{r}+c_{d F}\right)(a / 15)(N-1)$ Next, we estimate the 214 amount of food available in pools, $K_{p}$. The average diatom dry weight for rapids and 215 pools are 6.25 and $0.42\left[\mathrm{~g} / \mathrm{m}^{2}\right]$ (Miyadi 1960). Therefore, numerically, we get $K_{p}=$ $216[(0.42 \cdot 0.81) / 6.25)] K_{r}=0.054 K_{r}$. Now we estimate the fitness of a school fish, $W_{S}$. The relative feeding rate of 218 fish is estimated that $r=0.4$ from the relative sizes of territory holders and school fish 219 (Kawanabe 1969). Therefore, we get $W_{S}=0.454 K_{r}($ if $N \leq 1)$ or $0.454 K_{r} / N($ if $N>1)$. Finally, we estimate the fitness $W_{T}{ }^{*}$ of an attempted territory holder. We estimate the defense cost against school fish, $c_{d S}=10$ (Iguchi 1996). Therefore, the defense time of an attempted territory holder is $T_{d} *=(a / 15)(N-1)$. Then we derive numerically that $W_{T} *$ $=K_{r}-\left(K_{r}+c_{d s}\right)(a / 15)(N-1)$.

\section{Analysis and Results}

We compare the theory with empirical data which were obtained previously.

227 First we deal with the case that the fish density increases. The fitnesses of ayu fish 
229 floaters emerge in the pool. Above the breakdown point ( $N>N_{1}$ ), territory holders

230 should give up the territory and switch to schooling. The breakdown point is given by

$231 \quad N_{1}=5.486\left[\mathrm{fish} / \mathrm{m}^{2}\right]$ in the current model.

Table 2 shows the sensitivity of the attack rates and the defense cost against

floaters for their observed ranges and selected values. These results indicate that the

234 defense costs against floaters $\left(c_{d F}\right)$ have almost no effects on the outcomes. On the

235 other hand, the attack rates have much more profound effects on the optimal switching

236 points from 2 to 8 individuals. As our best estimate, we here keep the optimal switching

237 point for $a=3$ and $c_{d F}=0.1$.

Table 3 shows the observation data of fish state in increasing fish density.

239 From Table 3, territoriality is maintained for $N<4.1\left[\mathrm{fish} / \mathrm{m}^{2}\right]$ and schooling is seen for

$240 N>5.5\left[\right.$ fish $\left./ \mathrm{m}^{2}\right]$. These data mean $4.1<N_{1}<5.5$, which are consistent with the

241 theoretical estimation ( $\left.N_{1}=5.486\right)$. We should also note that the estimated breakdown

242 point is fairly robust in the estimated range of defense cost $c_{d s} \quad(=5 \sim 15)$.

Next, we deal with the case that the fish density decreases. At a high density,

244 all fish form a school $\left(N>N_{1}\right)$. In Fig. 4, the fitnesses in decreasing process are

245 depicted against the density $N$. When the density decreases below $N_{1}$, a school fish 
246 attempts to have a territory. The fitness of territory holders $\left(W_{T}\right)$ is not available for an

247 attempted territory holder. Even if $N<N_{1}$, the fitness of attempted territory holder

$248\left(W_{T}^{*}\right)$ may be smaller than that of school fish $\left(W_{S}\right)$. However, when $N<N_{2}$

$249 \quad\left(W_{T}^{*}>W_{S}\right)$, all school fish should switch to the territory option.

251 When $N>25.0$, all fish form school. In contrast, when $N<1.5$, all have territories. In 252 the intermediate case, the fitness $W_{S}$ is lower than $W_{T}$, but larger than $W_{T} *$

$253\left(W_{T}>W_{S}>W_{T}^{*}\right)$. Thus, few school fish attempt to have their territories, but they

254 cannot have stable territories. The data $N=5.0$ in Table 4 just indicate the emergence

255 of attempted territory holders (Th*). In this case, the territories are small and unstable

256 and a floater never emerges. This observation agrees with the theoretical prediction at

$257 N_{2}<N<N_{1}$. When the density further decreases at or below $N_{2}$, then every fish can

258 hold a territory. Hence, the fish switch to territoriality to keep a higher fitness. The

259 critical value may be close to $N_{T \max }$. Although $N_{T \max }$ is unity for natural river, it takes

260 a value larger than unity in experimental (rich food) condition. 


\section{Discussion and Conclusion}

We apply a fitness theory (Gross 1982; Tainaka et al. 2007; Tanaka et al. 2009)

to obtain both cost and benefit for three behavioral strategies: territory holder (Th),

265 floater (Fl), and school fish (Sc). The empirical data (see Tables 1 and 3) show the

behavior of ayu fish changes depending on its density. When the density $(N)$ increases,

the fish state changes as $\mathrm{Th} \rightarrow(\mathrm{Th}+\mathrm{Fl}) \rightarrow$ Sc (see Fig. $2 \mathrm{a} \rightarrow \mathrm{b} \rightarrow \mathrm{c}$ ). In contrast, in the

decreasing process of $N$, the phase changes as $\mathrm{Sc} \rightarrow$ Th $\quad$ (Fig. $2 \mathrm{c} \rightarrow \mathrm{a}$ ). The different

phase transitions between increasing and decreasing processes denotes the historical

effect (hysteresis). The breakdown point ( $\left.N_{1}\right)$ of territory should be larger than the

stage, but the territory formation is very hard against school fish in decreasing stage.

273 The value $N_{1}$ is determined by $W_{T}=W_{S} \quad$ [see Eq. (7)], while $N_{2}$ is determined by

$274 \quad W_{T} *=W_{S} \quad$ [see Eq. (10)].

276 (decrease) in density. When the density increases, the decision maker is not a floater,

277 but a territory holder (Th). When $W_{T}=W_{S}$, then the Th fish gives up the territoriality. In 
280 forced option. No fish wants to be a floater (loser)! Such a difference of transition

281 points causes the emergence of attempted territory holder ( $\left.\mathrm{Th}^{*}\right)$ in the decreasing

282 process of fish density. Even if a fish tries to hold a territory (Th*), school fish ignore

283 and swim over the territory and feed algae freely (Iguchi 1996; Tachihara and Kimura

284 1992). The fitness of Sc is much smaller than that of Th, but is larger than that of Th*.

285 This is because Th* defends against school fish, while Th defends against

286 scattered/sporadic floaters. Note that the defense against school fish is known to be very

287 hard (Iguchi 1996; Tachihara and Kimura 1992).

289 transition and magnetism. However, biological hysteresis was rare (Caraco 1980; Ronce

290 and Kirkpatrick 2001). Caraco (1980) dealt with dynamics of avian flocks foraging in

291 two patches, and reported the animal hysteresis. When a population size increases, the

292 incoming birds continue to join a single crowded feeding ground, until choosing a

293 vacant risky site becomes better than joining the already crowded patch. When the

294 population size decreases with birds leaving the feeding grounds, the number of birds in

295 both grounds becomes much less than the optimal flock size. The dynamics of flock

296 sizes are shifted from the optimal flock size (a single transition point) when flock sizes

297 are increasing or decreasing (Caraco 1980). The territoriality in ayu is another case of 
animal hysteresis. We show the different phase transitions as illustrated in Fig. 2.

Moreover, we report a distinct property never seen in other hysteresis systems. Namely,

300 we can see the historical effect in fish behaviors. In the decreasing process of the population size $N$, attempt territory holders (Th*) often appear instead of floaters. point ( $N_{1}$ ) of territoriality can be represented by $4.1<N_{1}<5.5$. This result is consistent with the theoretical estimation ( $\left.N_{1}=5.486\right)$. On the other hand, empirical data in decreasing stage (Table 4) suggest that $1.5<N_{2}<5.0$. This slightly differs from our prediction ( $N_{2} \approx 1$ ). The discrepancy may come from the estimation of parameters. In particular, the number of fish which intrudes into the territory of Th* may be overestimated [see Eq. (8)]. Our model is an extremely simple cost benefit model, so that other important factors are not included, e.g., individual variations in fish traits

310 (Katano and Iguchi 1996), interference by other fish species (Katano et al. 2000), the quality and size variations of the territories (Iguchi and Hino 1996), and the time scale of increasing/decreasing fish densities. The reproduction (regeneration) of algae after feeding may be also important, because the rate of regeneration is different between territorial feedings and school foraging (Katano et al. 2000). 
316 Acknowledgments

318 work was partly supported by grants-in-aids from the Ministry of Education, Culture,

319 Sports, Science and Technology of Japan to J. Y. and to K. T.

320 


\section{$322 \quad$ References}

323 Biggs, B. J. F., D. G. Goring, and V. I. Nokora. 1998. Subsidy and stress responses of

324 stream periphyton to gradients in water velocity as a function of community growth rate.

325 Journal of Phycology 34: 598-607.

326 Biggs, B. J. F., and C. W. Hickey. 1994. Periphyton responses to a hydraulic gradient in

327 a regulated river in New Zealand. Freshwater Biology 32: 49-59.

328 Brown, J. L. 1964. The evolution of diversity in avian territorial systems. Wilson Bull.

329 76: 160-169.

330 Brown, J. L. and G. H. Orians. 1970. Spacing patterns in mobile animals. Annual

$331 \quad$ Review of Ecology and Systematics 1:239-262.

332 Caraco, T. 1980. Stochastic dynamics of avian foraging flocks. American Naturalist

333 115: 262-275.

334 Clark C. W. and M. Mangel. 1986. The evolutionary advantages of group foraging.

335 Theoretical Population Biology 30: 45-75. 
336 Davies, N. B. and A. I. Houston. 1984. Territory Economics. In J. R. Krebs and N. B.

337 Davies (eds.), Behavioral Ecology: An Evolutionary Approach, 2nd ed., pp. 148-169.

338 Blackwell Scientific Publications, Oxford.

339 Ebersole, J. P. 1977. The adaptive significance of interspecific territoriality in the reef

340 fish Eupomacentrus leucosticus. Ecology 58: 914-920.

341 Foster, S. A. 1985. Group foraging by a coral reef fish : a mechanism for gaining access

342 to defended resources. Animal Behaviour 85: 782-792.

343 Gill, F. B., and L. L. Wolf. 1975. Economics of feeding territoriality in the

344 golden-winged sunbird. Ecology 56: 333-345.

345 Gross, M.R. 1982. Sneakers, satellites and parentals: polymorphic mating strategies in

346 North American sunfishes. Zeitschrift für Tierpsychol. 60: 1-26.

347 Gross, M. R. 1985. Disruptive selection for alternative life histories in salmon. Nature

$348 \quad 313,47-48$.

349 Iguchi, K. 1996. “The territory of Ayu” revisited. Gekkan Kaiyo 28: 281-285 (In

350 Japanese). 
351 Iguchi, K., and S. Abe. 2002. Territorial defense of an excess food supply by an algal 352 grazing fish, ayu. Ecological Research 17: 373-380.

353 Iguchi, K., and T. Hino. 1996. Effect of competitor abundance on feeding territoriality 354 in a grazing fish, the ayu Plecoglossus altivelis. Ecological Research 11: 165-173.

355 Iguchi, K., K. Ogawa, M. Nagae and F. Ito. 2003. The influence of rearing density on 356 stress response and disease susceptibility of ayu (Plecoglossus altiveilis). Aquaculture 357 220: 515-523.

358 Iguchi, K. and M. Yamaguchi. 1994. Adaptive significance of inter- and 359 intra-populational egg size variation in ayu Plecoglossus altivelis (Osmeridae). Copeia 360 1994: 184-190.

361 Katano, O., S. Abe, K. Matsuzaki, and K. Iguchi. 2000. Interspecific interactions 362 between ayu, Plecoglossus altivelis, and plae chub, Zacco platypus, in artificial streams.

363 Fisheries Science 66: 452-459 (In Japanese).

364 Katano, O., and K. Iguchi. 1996. Individual differences in territory and growth of ayu, Plecoglossus altivelis (Osmeridae). Canadian Journal of Zoology 74: 2170-2177. 
366 Katano, O., K. Uchida, and Y. Aonuma. 2004. Experimental analysis of the territorial

367 establishment of ayu, Plecoglossus altivelis. Ecological Research 19: 433-444.

368 Kawanabe, H. 1958. On the significance of the social structure for the mode of density

369 effect in a salmon-like fish, “Ayu”, Plecoglossus altivelis Temminkck et Schlegel.

370 Memoirs of the College of Science, University of Kyoto, Series B 25: 171-180 (In

371 Japanese).

372 Kawanabe, H. 1970. Social behaviour and production of ayu-fish in the River Ukawa

373 between 1955 and 1969, with reference to the stability of its territoriality. Japanese

374 Journal of Ecology 20: 144-151 (In Japanese).

375 Kawanabe, H. 1969. Kawa-to-Mizuumi-no-Sakanatati (Fishes in Rivers and Lakes).

376 Tokyo: Chuo Koronsha, Tokyo (In Japanese).

377 Kawanabe, H. 1973. What is the 'Nawabari (territory)' of ayu?: an attempt for the

378 theory of community. Kagaku 43: 74-83 (In Japanese).

379 Krebs, J. R. 1971. Territory and breeding density in the great tit, Parus major L.

380 Ecology 52: 2-22. 
381 Miyadi, D. 1960. Ayu-no-hanashi (Stories of Ayu). Iwanami-shoten, Tokyo (In

382 Japanese).

383 Mizuno, N., and H. Kawanabe. 1981. A topographical classification of streams, with an

384 introduction of the system widely used in Japan. I. Reach type, stream zone and stream

385 type. Verhandlungen der Internationale Vereinigung für Limnologie 21: 913.

386 Pyke, G. H. 1979. The economics of territory size and time budget in the golden-winged

387 sunbird. Am. Nat. 114: 131-145.

388 Pulliam H. R. and T. Caraco. 1984. Living in groups: Is there an optimal group size? In

389 J. R. Krebs and N. B. Davies (eds.), Behavioral Ecology: An Evolutionary Approach,

390 2nd ed., pp. 148-169. Blackwell Scientific Publications, Oxford.

391 Robertson, D. R., H. P. A. Sweatman, E. A. Fletcher and M. G. Cleland. 1976.

392 Schooling as a mechanism for circumventing the territoriality of competitors. Ecology

$393 \quad 57: 1208-1220$.

394 Ronce, O. and M. Kirkpatrick. 2001. When sources become sinks: migrational

395 meltdown in heterogeneous habitats. Evolution 55: 1520-1531. 
396 Schaller, G. B. 1972. The Serengeti Lion: A Study of Predator-Prey Relations. Chicago

397 University Press, Chicago.

398 Stephens, D. W. and J. R. Krebs. 1986. Foraging Theory. Princeton University Press,

399 Princeton.

400 Tachihara, K., and S. Kimura. 1992. The ecological significance of the yellow oval

401 marks on body of landlocked ayu in Lake Ikeda. Nippon Suisan Gakkaishi 58: 1191 (In

402 Japanese).

403 Tainaka, K., J. Yoshimura and M. L. Rosenzweig. 2007. Do male orangutans play a 404 hawk-dove game? Evolutionary Ecology Research 9: 1043-1049.

405 Takahashi, I., and K. Azuma. 2006. Kokomade Wakatta Ayu No Hon (The Up-to-now

406 Knowledge Book of Ayu). Tsukiji-shokan, Tokyo, xviii+267pp. (In Japanese).

407 Tanaka, Y., T. Hayashi, D. G. Miller III, K. Tainaka and J. Yoshimura. 2009. Breeding 408 games and dimorphism in male salmon. Animal Behaviour 77: 1409-1413. 


\section{Tables}

413 Table 1. The attack frequency of a territory holder against an intruder at low density in 414 experimental running-water pools of $2 \times 5$ square meter in 1991 in Japan (Iguchi 1996).

415

416

417

418

419

420

421

422

423

424

425

426

427

428

429

430

431

432

\begin{tabular}{ccccccc}
\hline TF & NT & NF & F/T & $\begin{array}{c}\text { Territory size } \\
{\left[\mathrm{m}^{2}\right]}\end{array}$ & $\begin{array}{c}\text { Attack frequency } \\
{[1 / \mathrm{min}]}\end{array}$ & $\begin{array}{c}\text { Attack frequency } \\
{[1 / \mathrm{min} / \text { holder }]}\end{array}$ \\
\hline 3 & 2 & 1 & 0.5 & 3.68 & 2.12 & 4.24 \\
& & & 2.00 & 3.14 & 6.28 \\
\hline 6 & 5 & 1 & \multirow{2}{*}{0.2} & 0.32 & 0.55 & 2.75 \\
& & & 0.96 & 0.35 & 1.75 \\
& & & 0.80 & 0.74 & 3.70 \\
& & & 0.40 & 0.60 & 3.00 \\
& & & 0.56 & 0.40 & 2.00 \\
& & & & & \\
\end{tabular}

Entries are: TF: total fish; NT: number of territory holders; NF: floater number; F/T: the ratio of floater per a territory holder. The average attack frequency/min/holder is 3.39 times. Estimation of attack frequency is based on the 5 minutes observation of every fish per day. Attack includes against both floaters and other territory holders. 
433 Table 2. The switching point from territory holders (T) to school (S) in relation to the 434 attack rates $(a)$ and the defense cost against floaters $\left(c_{d F}\right)$. The unit is the number of 435 individuals /unit area.

436

437

438

Defense cost

Attack cost

439

440

against floaters

1.8

3

6.3

441

\begin{tabular}{cccc}
\hline 0.01 & 8.8 & 5.6 & 3.0 \\
0.1 & 8.6 & 5.4 & 3.0 \\
0.2 & 8.4 & 5.3 & 2.9 \\
\hline
\end{tabular}

444

445 
446 Table 3. The existence of territoriality against an increasing fish density.

\begin{tabular}{|c|c|c|c|c|c|}
\hline Year & $\begin{array}{c}\text { River or } \\
\text { Pond }\end{array}$ & $\begin{array}{l}\text { Natural or } \\
\text { experiment }\end{array}$ & $\begin{array}{c}\text { Density } \\
N\left[1 / \mathrm{m}^{2} \text { rapids }\right]\end{array}$ & $\begin{array}{l}\text { State } \\
\text { of fish }\end{array}$ & Reference \\
\hline 1955 & Ukawa & Natural & 5.5 & School & {$[1]$} \\
\hline 1956 & Ukawa & Natural & 0.9 & Territory & {$[1]$} \\
\hline 1957 & Ukawa & Natural & 0.3 & Territory & {$[1]$} \\
\hline 1958 & Inukai & Experiment & 4.1 & Territory & {$[1]$} \\
\hline 1987 & Pond & Experiment & 195.2 & School & {$[2]$} \\
\hline 1987 & Pond & Experiment & 97.6 & School & {$[2]$} \\
\hline 1989 & Pond & Experiment & 120.4 & School & {$[2]$} \\
\hline 1989 & Pond & Experiment & 25.0 & School & {$[2]$} \\
\hline 1991 & \multicolumn{2}{|c|}{ Experimental stream } & 1.0 & Territory & [3] \\
\hline 1991 & \multicolumn{2}{|c|}{ Experimental stream } & 0.6 & Territory & [3] \\
\hline 1999 & Pond & Experiment & 1250.0 & School & [4] \\
\hline 1999 & Pond & Experiment & 400.0 & School & {$[4]$} \\
\hline 1999 & Pond & Experiment & 100.0 & School & [4] \\
\hline
\end{tabular}


468 Table 4. The state of fish in an decreasing stage.

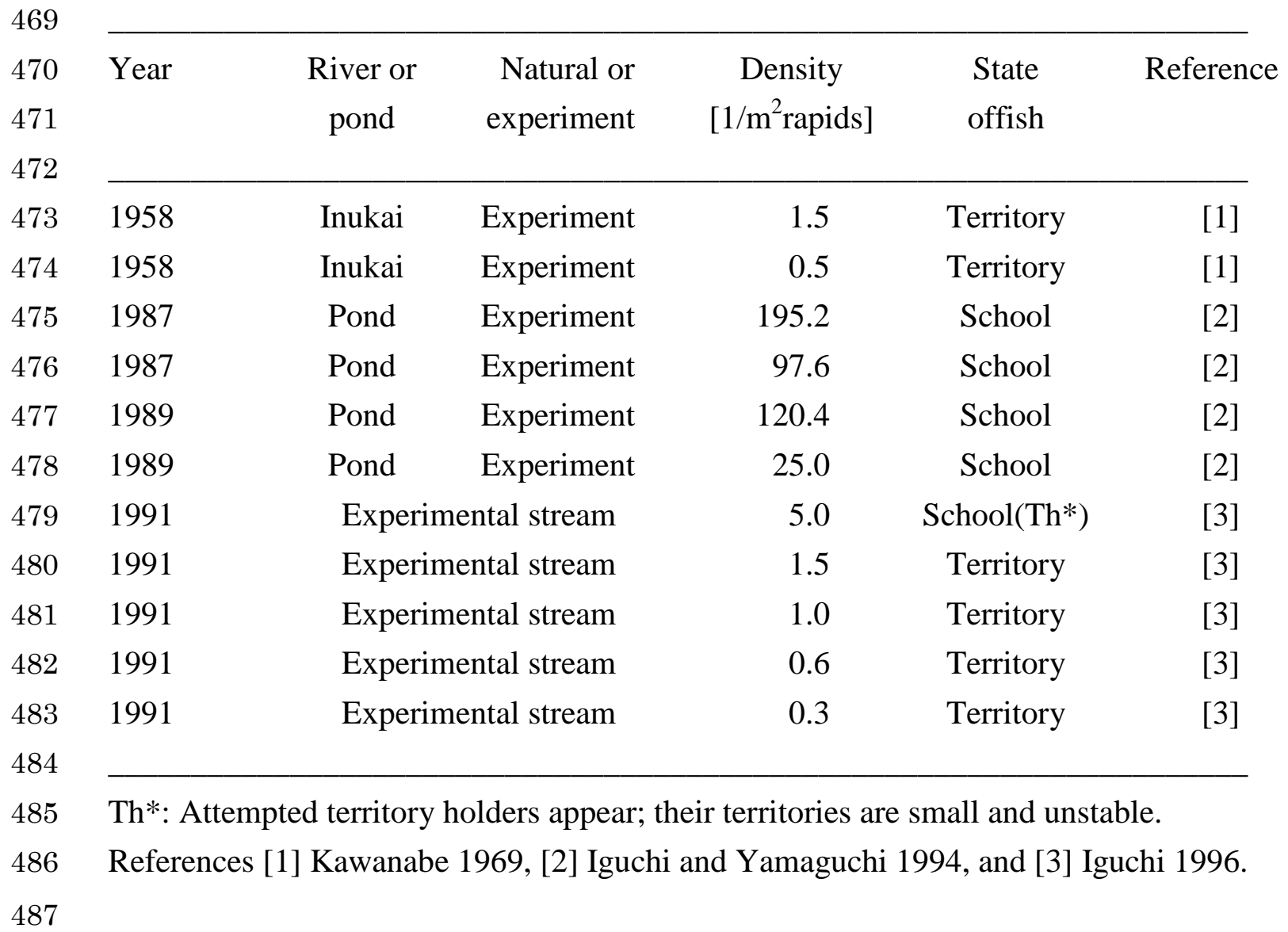


490 Fig. 1. The territoriality in ayu. (a) Two fish check with each other at the boundary of

491 both territories. (b) A territory holder (behind) attacks against an intruder.

493 Fig. 2. The breakdown and formation models of territoriality. When the fish density

494 increases, phases (stages) change as $\mathrm{a} \rightarrow \mathrm{b} \rightarrow \mathrm{c}$. Stage a: when the density is low, all fish hold a territory. Stage b: when the density increases, some fish become a floater. Stage c: when the density further increases, all the territories break down and fish swim in schools. When the fish density decreases, the change $\mathrm{c} \rightarrow$ a occurs: when the density decreases to a low density, all the fish begin to form a territory almost simultaneously.

Fig. 3. The theoretical result with increasing of fish density. The fitnesses of a territory

501 holder ( $W_{T}$, red), a floater ( $W_{F}$, blue) and a school fish ( $W_{S}$, green) are depicted against

502 the density ( $N$ ). The maximum density (capacity) of territory is assumed $N_{T \max }=1$, and the transition (breakdown) point is given by $N_{1}=5.486$. The unit for fitness is 
504 (gram diatom food)/[day $\left(1 \mathrm{~m}^{2}\right.$ rapids $+0.81 \mathrm{~m}^{2}$ pools) $]$. The parameter settings are: $a=3, c$

$505=0.1, \quad K_{r}=3.3, \quad K_{p}=0.1782$ and $r=0.4$.

506

507 Fig. 4. The result in decreasing stage. The fitnesses of an attempted territory holder

508 ( $W_{T} *$, solid purple line) and a school fish ( $W_{S}$, solid green curve) are plotted against

509 the density $(N)$. For the comparison, the fitness of a territory holder $\left(W_{T}\right.$, broken red

510 line) is shown. The transition (formation) point is represented by $N_{2}$ which is much less

511 than the breakdown point $\left(N_{1}\right)$. The parameter settings are the same as in Fig. 3.

512 
513

514

$515 \quad$ Fig. 1

$516 \quad$ (a)

(b)

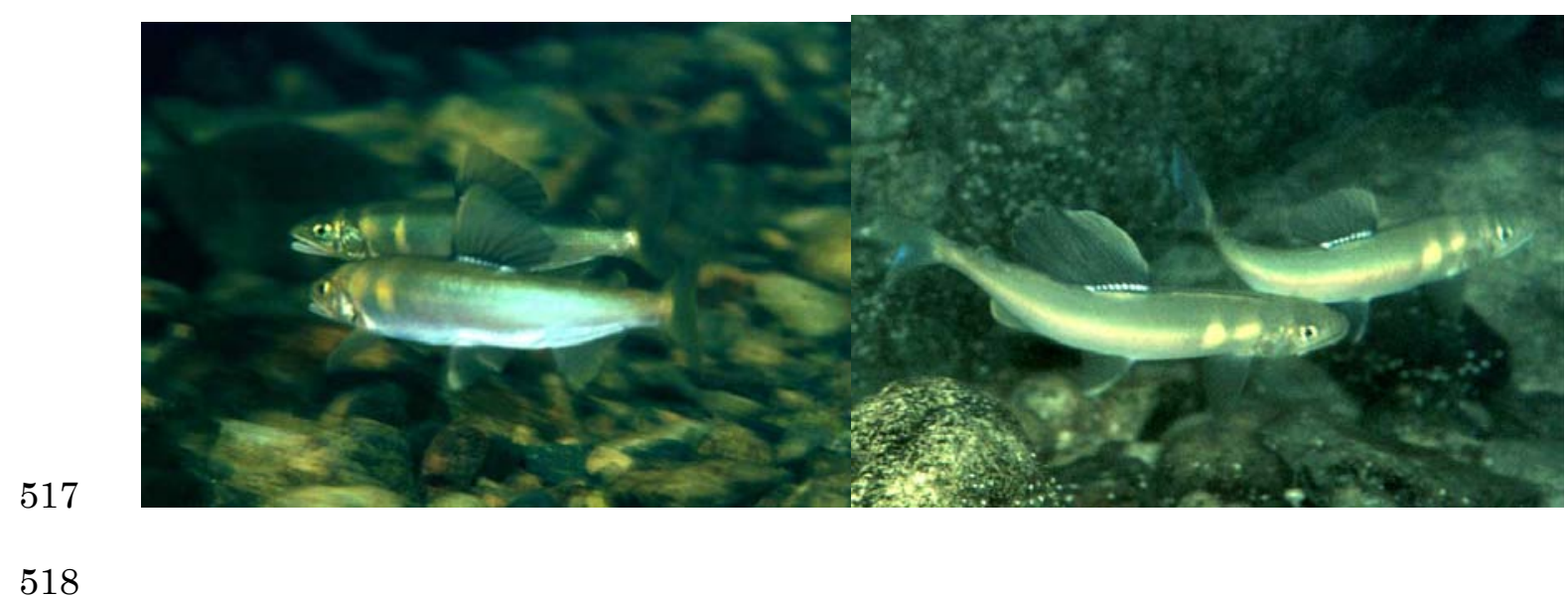


$521 \quad$ Fig. 2

Floater

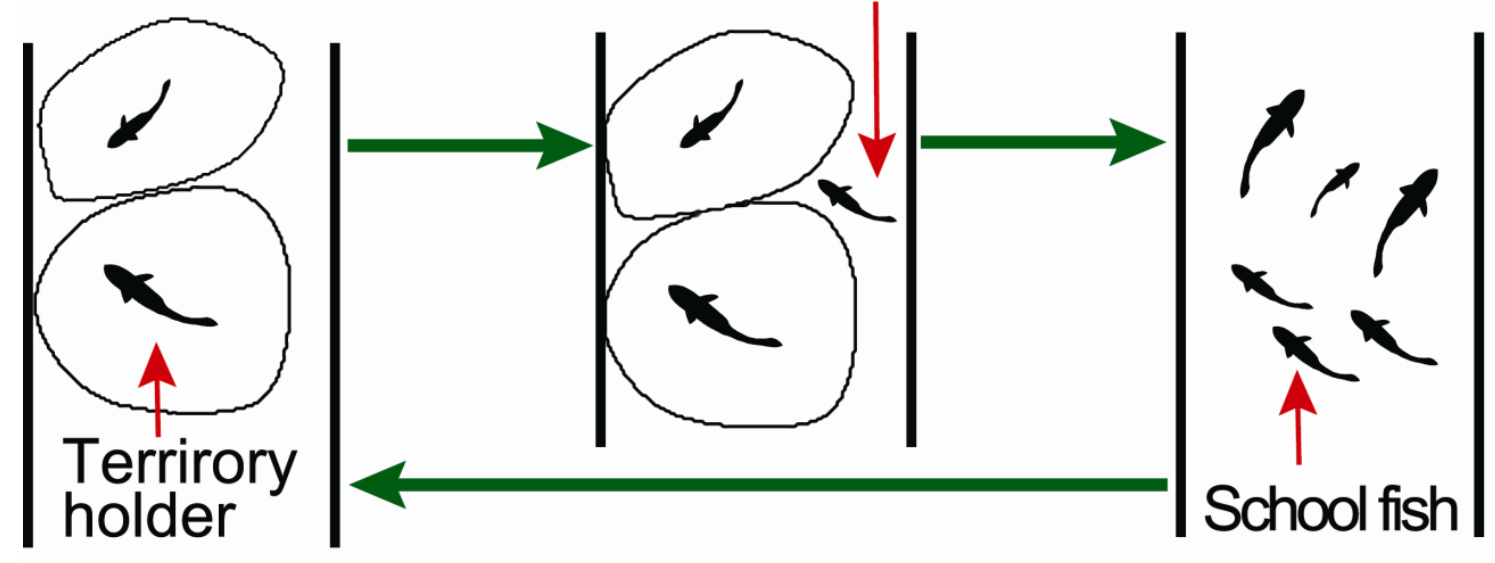

a

b

C 


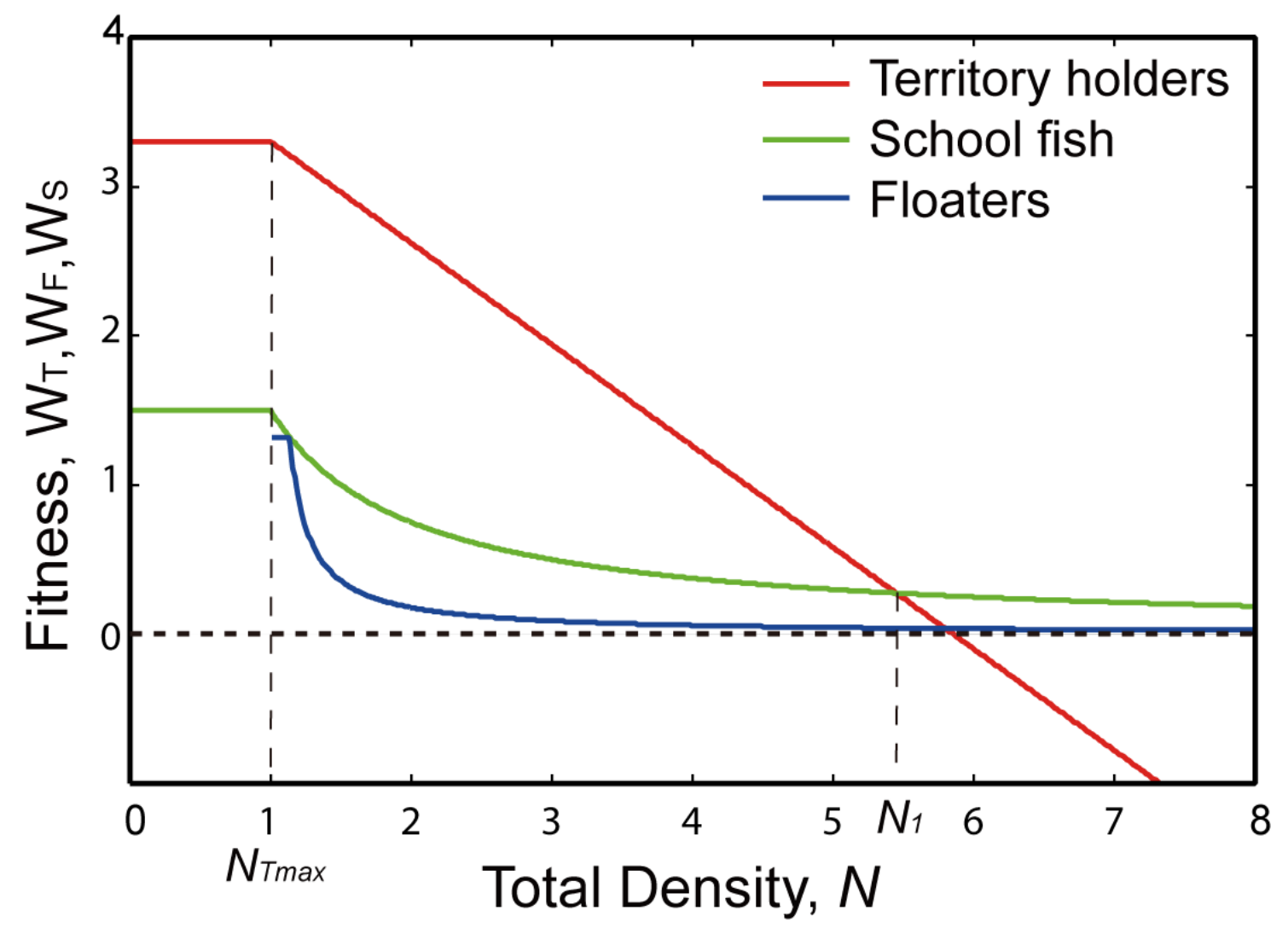

527 
$531 \quad$ Fig. 4

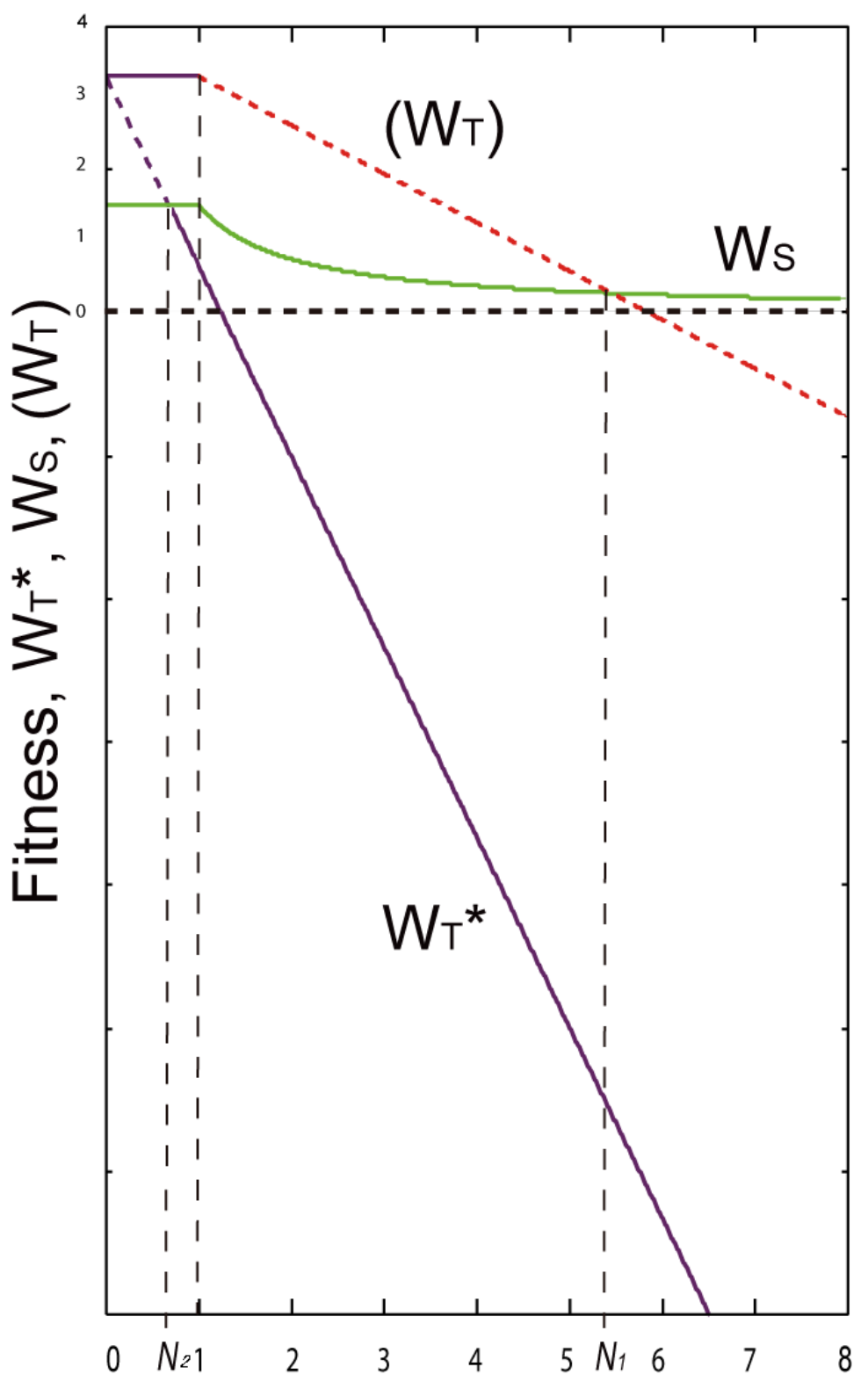

Total Density, $N$ 